\title{
Weldability of Duplex Stainless Steels - Thermal Cycle and Nitrogen Effects
}

\author{
Duplex stainless steel weld microstructures were investigated as a \\ function of weld thermal cycles and shielding gas nitrogen content
}

\author{
BY B. VARBAI, Y. ADONYI, R. BAUMER, T. PICKLE, J. DOBRÁNSZKY, AND K. MÁLINGER
}

\begin{abstract}
Much development work has been performed worldwide on the welding of duplex stainless steels (DSSs), where losses in base metal nitrogen during welding have been compensated by filler metal and nitrogen additions to the shielding gas. However, some heat-affected zone (HAZ) microstructural changes have not always responded consistently to nitrogen mixtures added to the shielding gas. In this work, DSS weld microstructures were investigated as a function of weld thermal cycles and shielding gas nitrogen content. Physical simulations, actual gas tungsten arc welding (GTAW) in controlled atmospheres, and entrapped nitrogen measurements were used to relate to the weld austenite-to-ferrite (A/F) phase ratios. Results showed the thermal cycles had a stronger effect on the weld $A / F$ ratio than shielding gas nitrogen content. Physical simulations and actual GTAW trials also showed the $\mathrm{A} / \mathrm{F}$ ratio changes in the opposite way in the fusion zone than in the HAZ. Reheating was also found to have an important effect on the microstructure. The above findings should allow fabricators to better design the welding process with DSS. Better control of nitrogen-containing shielding gas mixtures, along with heat input limitations, should result in more consistent weld properties and wider use of DSS by industry.
\end{abstract}

\section{KEYWORDS}

- Duplex Stainless Steel • Physical Simulation

- Gas Tungsten Arc Welding • Microstructure

- Phase Transformation

\section{Introduction}

\section{Background}

All duplex stainless steels (DSSs) contain some nitrogen, typically in the 0.15 to $0.35 \mathrm{wt}-\%$ range (Ref. 1 ) with higher values found in the lean, super, and hyper duplex grades. The most widely used DSS type 2205 (UNS S32205/EN 1.4462) contains $0.14-0.20 \mathrm{wt}-\%$ nitrogen, which effectively replaces nickel with this less expensive alloying option. The addition of nitrogen strengthens both ferrite and austenite phases by dissolving as an interstitial alloying element in solid solutions. Nitrogen is a well-known strong austenite former, and it increases the base metal yield and ultimate tensile strength.
To quantify the austenite stabilizing effect of nitrogen, the nickel equivalent formula can be used. According to the WRC-1992 (Ref. 2) diagram's formula, nitrogen is 20 times more potent than nickel is as an austenite stabilizer. Other resources indicate a 30 times higher potency than $\mathrm{Ni}$ (Ref. 3 ). Adding nitrogen content increases the austenite transformation temperature and promotes austenite formation at high temperatures during the cooling cycle (Ref. 4).

The DSSs were originally developed not only for their higher strength, but also their resistance against stress corrosion cracking when compared to austenitic stainless steels. The DSSs were also found to have good resistance against pitting corrosion (Ref. 5). Nitrogen also helps in preventing the precipitation of brittle intermetallic phases, such as $\sigma$ and $\chi$, by reducing chromium partitioning (Refs. 5 , 6). However, if some $\mathrm{Cr}$-rich nitride precipitates form in the ferritic phase, they can decrease ductility, toughness, and corrosion resistance (Refs. 7-9).

Nitrogen can be lost from the base metal during fusion welding as it evaporates in the heat generated by the electric or thermal plasma. For practical solutions to this $\mathrm{N}$ loss (N refers to monatomic nitrogen, while $\mathrm{N}_{2}$ refers to diatomic nitrogen), welding handbooks and recommendations often offer a narrow technological window in case of using nitrogen as shielding or backing gas. They also recommend using $2-5 \%$ of $\mathrm{N}_{2}$ into the shielding gas to compensate for the nitrogen loss (Ref. 10). Some researchers (Refs. 11, 12) used 10-20\% nitrogen content in argon shielding gases to compensate the nitrogen loss in the weld metal (WM).

The kinetics of nitrogen reactions are more complicated and very dependent on solidification and cooling rates. Therefore, a brief review of nitrogen/molten metal reactions follows in the following order: 1 ) sources of atomic nitrogen in fusion welding, 2) nitrogen absorption into or rejection from the weld pool, 3) nitrogen solubility in the molten metal, 4) nitrogen entrapment under nonequilibrium solidification, and 5) nitrogen's role in subsequent solid-state diffusion and reactions upon weld cooling.

\section{Literature Review, Problem Statements}

Review of other studies (Refs. 11, 13, 14-25), which describe the impact of nitrogen in DSS welding, revealed a strong emphasis on explaining nitrogen solubility, solidstate ferrite-to-austenite phase transformations, and gas 


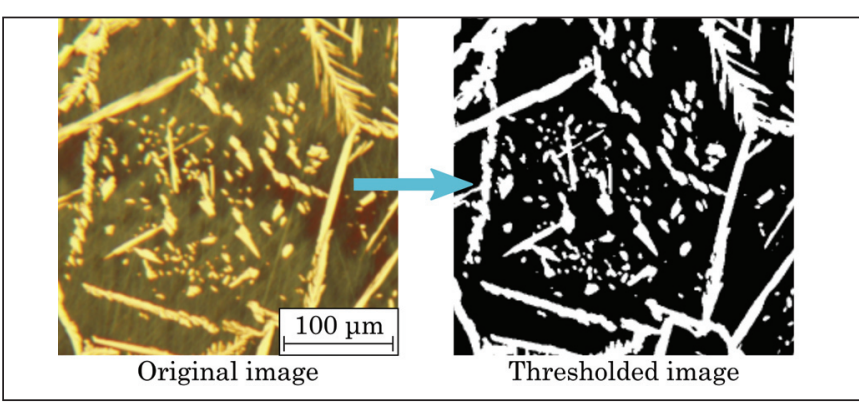

Fig. 1-Optical microscope image of optimally etched (Ref. 26) DSS 2205 weld metal and digitally processed image for austenite fraction determination. (The images were taken at the same magnification.)

porosity formation. Yet the basic understanding of nitrogen use in fusion welding is still not complete.

First, the established models are referring to solubility and diffusion kinetics of atomic nitrogen in the solid state, not in the liquid. Second, most papers do not differentiate between the role of atomic and diatomic nitrogen in the case of molten state during fusion welding. Third, there is no differentiation on the solidification rate driven vs. the solid state (diffusion driven) phase transformations, which are governed by the subsequent cooling rate. Fourth, the role of free, dissolved nitrogen in reheating, simulating multipass welding is also not well covered in the open literature. Detrimental phase transformations can form during multipass welding, such as chromiumnitride precipitation and secondary austenite formation, which can lead to a significant unbalance between the austenite-to-ferrite $(\mathrm{A} / \mathrm{F})$ ratios. Finally, understanding complicated thermal effects, dilution, filler metal nitrogen content, heat input, reheat cycles, and the effect of nitrogen backing gas is not complete from the open literature. What is known provides solutions in a narrow operational envelope (heat input, type of filler metal, shielding gas, chamfering, and so on) for industrial partners.

\section{Objectives}

In conclusion, the present research was needed for a more comprehensive understanding of the role of nitrogen on DSS welding. The aim of this work was to systematically separate

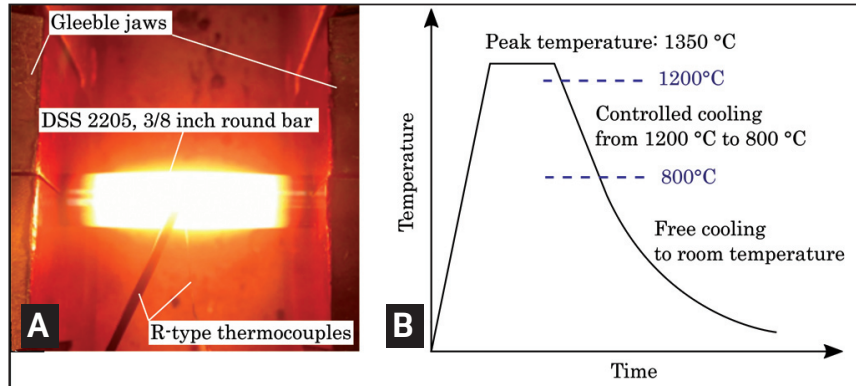

Fig. $2-A-$ Simulation of HAZ in Gleeble ${ }^{\circledR}$ setup; B schematic of used thermal cycle with special emphasis on the $1200^{\circ}$ to $800^{\circ} \mathrm{C}$ cooling rate.

the effects of atomic from molecular nitrogen effects in fusion welding of DSSs. Heat input, solidification and cooling rates, and reheating effects were to be included in the study, while analyzing the effect of nitrogen additions on microstructure via the shielding gas, filler metal, and multiple-pass welding.

\section{Experimental Procedures}

\section{Chemical Composition of Duplex Stainless Steel Grades}

To investigate the effects of nitrogen and thermal cycles on duplex stainless steels, three different types of DSSs were used in our research (Table 1 , chemical composition by manufacturer): lean duplex grade UNS S82441 (LDX 2404) sheet in $3 \mathrm{~mm}$ thickness, standard duplex grade UNS S32205 (DSS 2205) sheets in 2 and $6 \mathrm{~mm}$ thicknesses, and 3/8-in. (9.525-mm) rod form and one superduplex grade UNS S32750 (SDSS 2507). All of the utilized grades contain a high amount of nitrogen (0.160-0.276 wt-\%) as the alloying element. The base metals were received in the annealed condition as coming from the manufacturer.

\section{Microstructure Evaluation}

Optical microscopy was used to evaluate the weld metal and heat-affected zone (HAZ) microstructures. The samples were etched using Beraha's II reagent with the composition of 85$\mathrm{mL}$ distilled water, $15-\mathrm{mL} \mathrm{HCl}$, and 1- $\mathrm{g} \mathrm{K}_{2} \mathrm{~S}_{2} \mathrm{O}_{5}$. The etchant

Table 1 - Main Alloying Elements of the Used DSS Grades*

\begin{tabular}{|c|c|c|c|c|c|c|c|c|c|c|}
\hline \multirow[t]{2}{*}{ Grade } & \multirow[t]{2}{*}{ Form } & \multicolumn{9}{|c|}{ Main Alloying Elements (wt-\%) } \\
\hline & & $\mathrm{Cr}$ & $\mathrm{Ni}$ & $\mathrm{Mn}$ & Mo & $\mathrm{N}$ & C & $\mathrm{Si}$ & $\mathrm{Cu}$ & $\mathrm{Fe}$ \\
\hline \multirow{2}{*}{$\begin{array}{l}\text { LDX } \\
2404\end{array}$} & 3-mm sheet & 24.11 & 3.56 & 3.12 & 1.62 & 0.276 & 0.020 & 0.70 & 0.40 & bal. \\
\hline & 2-mm sheet & 22.41 & 5.78 & 1.25 & 3.10 & 0.191 & 0.020 & 0.35 & 0.32 & bal. \\
\hline \multirow{2}{*}{$\begin{array}{l}\text { DSS } \\
2205\end{array}$} & 6-mm sheet & 22.37 & 5.76 & 1.36 & 3.14 & 0.160 & 0.020 & 0.38 & 0.30 & bal. \\
\hline & $\begin{array}{l}\text { 3/8-in.- (9.525-mm-) } \\
\text { diameter rod }\end{array}$ & 22.21 & 5.95 & 1.55 & 3.10 & 0.160 & 0.019 & 0.51 & 0.32 & bal. \\
\hline $\begin{array}{l}\text { SDSS } \\
2507\end{array}$ & 6-mm sheet & 25.04 & 6.93 & 0.76 & 3.78 & 0.270 & 0.016 & 0.44 & 0.40 & bal. \\
\hline
\end{tabular}




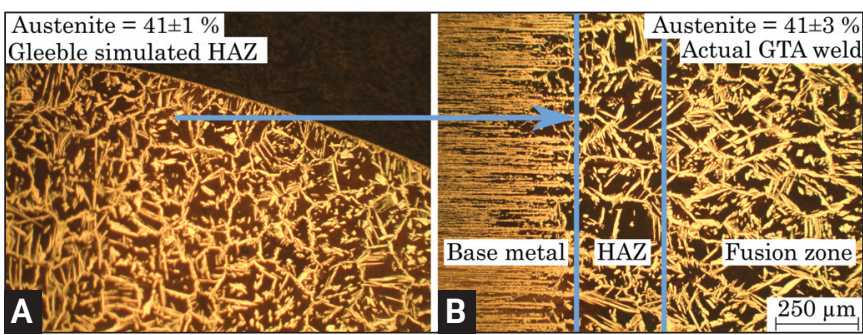

Fig. 3-A - Comparison of DSS 2205 samples between Gleeble ${ }^{\circledR}$ physically simulated and $B$ - actual gas tungsten arc welded HAZ microstructures with approximately the same cooling rates. (The images were taken at the same magnification.)

tints the ferrite (bcc lattice structure) phase dark and leaves the austenite (fcc lattice structure) phase bright, which is suitable for austenite fraction measurements.

For austenite fraction measurements, the Image Pro ${ }^{\circledR}$ image analysis software, Feritscope ${ }^{\circledR}$ measurements, and manual point count method according to the ASTM E562 Standard were used. To validate the image analysis results to the Feritscope ${ }^{\circledR}$ measurements, a double-etching method with Beraha's II reagent was used, which results in high contrast between the austenite and ferrite phases - Fig. 1. The developed method for optimal etching and image analysis can be found from previous work (Ref. 26).

To validate the developed process of image analysis, quantitative optical microscopy was also used to determine the volume fraction by a manual point count method, according to the ASTM E562 Standard (Ref. 27). In this method, an array of points formed by a grid line is superimposed upon a magnified image, and the number of points falling within the microstructural constituent of interest is counted and averaged for a selected number of fields. If the amount of volume fraction of interest is more than $20 \%$ (which is true for almost all cases of DSS welds), 100 points should be evaluated of 20 fields for a $10 \%$ relative accuracy. While the point-counting method is acceptable according to standards, this analysis is slow, highly subjective, and not repeatable for all users. In this research, 108 intersection points were evaluated in each of the 10 images for comparison to the image analysis and Feritscope ${ }^{\circledR}$ techniques.

\section{Total Nitrogen Content Measurements}

The total dissolved nitrogen content measurement was performed according to the ASTM E1019 Standard (Ref. 28). Four samples were machined out from the weld metal or the simulated HAZ and burned in a Horiba Emga 620-W nitrogen analyzer. The total nitrogen content was measured with an inert gas thermal conductivity detection method. The measurement range was $0-5000$ ppm with the minimum accuracy of $1.5 \mathrm{ppm}$ and sensitivity of $0.01 \mathrm{ppm}$.

\section{Heat-Affected Zone Simulations in a Gleeble ${ }^{\circledR}$ Physical Simulator}

For HAZ simulations, the DSS 2205 rods in $3 / 8$ in. (9.525 $\mathrm{mm}$ ) diameter were reheated in a Gleeble ${ }^{\circledR} 1500$ physical simulator in $99.996 \%$ pure argon atmosphere. The samples

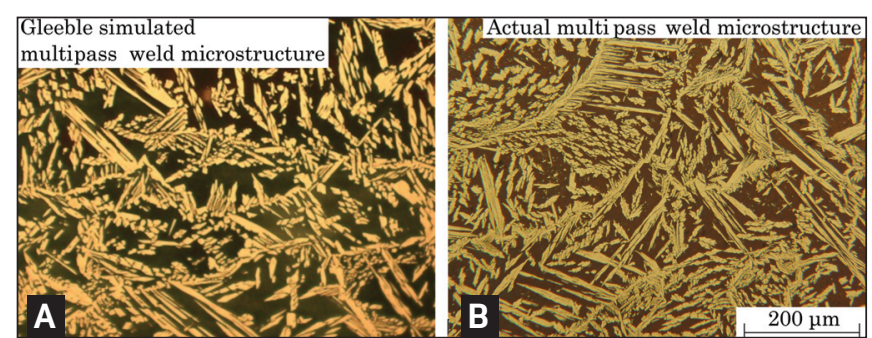

Fig. 4-A - Comparison of reheated weld metal microstructures of DSS 2205 samples between a Gleeble ${ }^{\circledR}$ physically simulated and B - actual GTA welded reheated by the subsequent passes. (The images were taken at the same magnification.)

were heated to $1350^{\circ} \mathrm{C}$ peak temperature under $10 \mathrm{~s}$ and kept for $1 \mathrm{~s}$ at the maximum temperature to develop an almost fully ferritic initial microstructure. Different controlled cooling rates were chosen between $1350^{\circ}$ and $800^{\circ} \mathrm{C}$, and then air cooled to room temperature - Fig. 2.

The used cooling rates were as follows: $10^{\circ}, 19^{\circ}, 27^{\circ}, 36^{\circ}$, $54^{\circ}, 80^{\circ}, 113^{\circ}, 149^{\circ}$, and $500^{\circ} \mathrm{C} / \mathrm{s}$ (water quenched) to $800^{\circ} \mathrm{C}$ $\left(\mathrm{dT}_{12 / 8}\right)$ following free cooling to room temperature. The temperature measurement was done using R-type thermocouples. Typical simulated HAZ and actual HAZ microstructures were compared (e.g., Fig. 3) and good correlations in microstructure and $\mathrm{A} / \mathrm{F}$ phase ratios (measured by the image analysis method) were found. For comparison of the Gleeble ${ }^{\circledR}$ simulated sample (with $54^{\circ} \mathrm{C} / \mathrm{s}$ cooling rate), singlepass autogenous gas tungsten arc welded 2-mm-thick DSS 2205 sheets were used, with an average measured $51^{\circ} \mathrm{C} / \mathrm{s}$ cooling rate $\left(\mathrm{dT}_{12 / 8}\right)$ in the $\mathrm{HAZ}$.

\section{Pseudo-Nitriding Simulations in a Gleeble ${ }^{\circledR}$ Physical Simulator}

The pseudo-nitriding experiments were done on the DSS 2205 rod samples using a constant peak temperature of $1350^{\circ} \mathrm{C}$, different peak temperature holding times, and subsequent $50^{\circ} \mathrm{C} / \mathrm{s}$ controlled cooling rate $\left(\mathrm{dT}_{12 / 8}\right)$. Using pure argon gas for comparison, the Gleeble ${ }^{\circledR}$ chamber was flooded with $100 \%$ nitrogen for short times (total times 5 to 60 s), which is much longer than used in real-life welding. These samples were cross sectioned and the thickness of the pseudo-nitrided outside diameter (OD) layer was measured for each sample. The diffusion distance of the monatomic nitrogen $(\mathrm{N})$ was calculated, using the 1D diffusion model with the diffusion coefficient $\left(\mathrm{m}^{2} / \mathrm{s}\right)$ of nitrogen in ferrite phase $\mathrm{D}_{\mathrm{N}}=4.64 \cdot 10^{-7} \cdot \mathrm{e}^{-10223.7 / \mathrm{T}}$ (Ref. 29).

\section{Single-Pass Autogenous GTAW with Argon Shielding Gas}

To investigate the effects of arc energy (cooling rate) on the weld metal A/F phase ratio and nitrogen loss, the 3-mmthick LDX 2404 sheets were autogenously gas tungsten arc welded with argon shielding gas, with the flow rate of 25 $\mathrm{ft}^{3} / \mathrm{h}(12 \mathrm{~L} / \mathrm{min})$ in all cases and without filler metal. The LDX 2404 base material was chosen because of its highest initial nitrogen content in the base metal (0.276 wt-\%, Table 1) among the investigated grades, thus the nitrogen loss in 


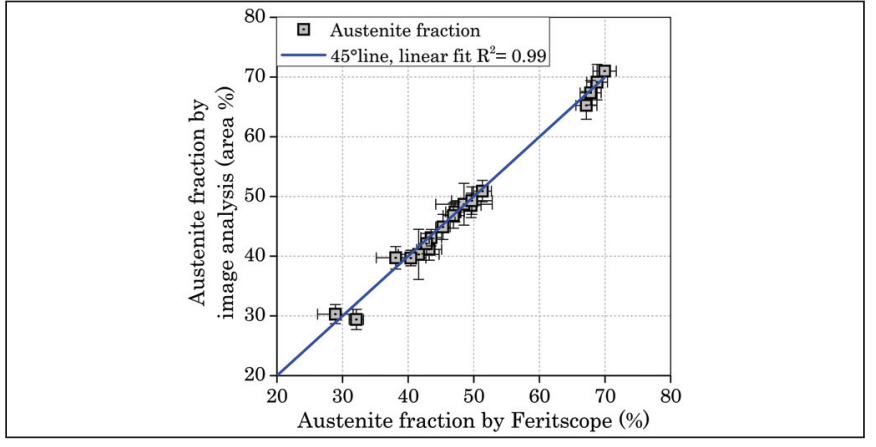

Fig. 5 - Comparison of the image analysis and Feritscope ${ }^{\circledR}$ methods to determine austenite fraction.

the weld metal was expected to have a significant effect on the $\mathrm{A} / \mathrm{F}$ phase ratio. The used tungsten electrode was $2 \%$ thoriated in $1 / 8$ in. $(3.2 \mathrm{~mm}$ ) diameter and ground to a $40-\mathrm{deg}$ electrode angle. The arc length was constant $2 \mathrm{~mm}$. The used arc energies were as follows: $0.33,0.43,0.58,0.64$, 0.86 , and $0.90 \mathrm{~kJ} / \mathrm{mm}$, equal to $8.4,10.9,14.7,16.3,21.8$, and $22.8 \mathrm{~kJ} / \mathrm{in}$., respectively. For simplicity, the thermal efficiency was taken as 1.0 for the arc energy calculations.

Another set of autogenous gas tungsten arc welding (GTAW) trials were done on the 6-mm-thick DSS 2205 sheets with argon shielding gas, with the same flow rate of $25 \mathrm{ft}^{3} / \mathrm{h}(12 \mathrm{~L} / \mathrm{min})$ in all cases, using these even improper arc energies: $0.25,0.85,1.00,1.57,2.36$, and $2.95 \mathrm{~kJ} / \mathrm{mm}$, equal to $6.25,21.25,25.0,40.0,60.0$, and $75.0 \mathrm{~kJ} / \mathrm{in}$., respectively. The purpose of this study was to compare the austenite fraction changes (as a function of the cooling rate) in the HAZ (Gleeble ${ }^{\circledR}$ simulated) and WM (actual GTA welded). The temperature readings in the HAZ were done using K-type thermocouples, which was supported by a FLIR-type thermal imaging camera (emissivity constant of 0.25). The root side of the welds were protected with argon shielding through a diffuser box.

\section{Single-Pass Autogenous GTAW with Different Nitrogen Content in the Shielding Gas}

For the investigation of the nitrogen content $\left(\mathrm{N}_{2}\right)$ in the shielding gas, GTAW trials were done on the 2-mm-thick DSS 2205 and LDX 2404 sheets. The used tungsten electrode was $2 \%$ thoriated with $1 / 8 \mathrm{in}$. (3.2 $\mathrm{mm}$ ) diameter and ground to a $40-$ deg electrode angle. The arc length was initially $2 \mathrm{~mm}$, which was controlled with the automatic arc voltage system to keep a constant arc energy. For grade DSS 2205, the used arc energy was constant $0.43 \mathrm{~kJ} / \mathrm{mm}(11 \mathrm{~kJ} / \mathrm{in}$.) with the shielding gases of $\mathrm{Ar}, \mathrm{Ar}+2 \mathrm{~N}_{2}, \mathrm{Ar}+5 \mathrm{~N}_{2}$, and $\mathrm{Ar}+10 \mathrm{~N}_{2}$.

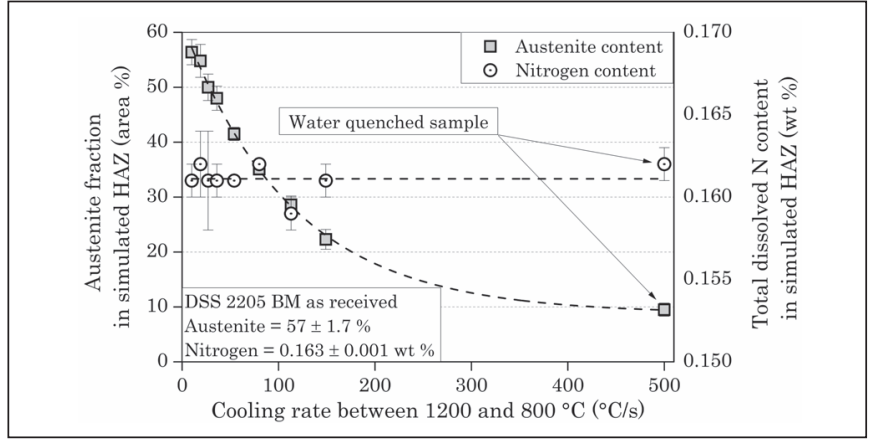

Fig. 6 - Gleeble ${ }^{\circledR}$ simulated HAZ austenite volume fractions and the total dissolved nitrogen content as a function of the $\mathrm{d} T_{12 / 8}$ cooling rate.

For grade LDX 2404, the used arc energy was constant $0.86 \mathrm{~kJ} / \mathrm{mm}(21.8 \mathrm{~kJ} / \mathrm{in}$.), using even improper shielding gas mixtures of $\mathrm{Ar}, \mathrm{Ar}+2 \mathrm{~N}_{2}, \mathrm{Ar}+5 \mathrm{~N}_{2}, \mathrm{Ar}+10 \mathrm{~N}_{2} \mathrm{Ar}, \mathrm{Ar}+20 \mathrm{~N}_{2}$, and even $\mathrm{Ar}+50 \mathrm{~N}_{2}$.

For both cases, the root side was protected using argon shielding. The shielding gas flow rate was $25 \mathrm{ft}^{3} / \mathrm{h}(12 \mathrm{~L} / \mathrm{min})$ in all cases.

\section{Multipass Welding Simulations in a Gleeble ${ }^{\circledR}$ Physical Simulator}

One set of autogenous GTA welded DSS 2205 samples, welded with different nitrogen content in the shielding gas (four samples, described in the previous section), were reheated in a Gleeble ${ }^{\circledR}$ physical simulator in argon atmosphere. The reheating was done with $1250^{\circ} \mathrm{C}$ peak temperature, 1-s holding time, and $50^{\circ} \mathrm{C} / \mathrm{s}$ cooling rate to $800^{\circ} \mathrm{C}$, as this cooling rate was measured in the HAZ during the actual GTAW. The purpose of this experiment was to investigate the effect of multiple thermal cycles (e.g., multipass welding) on the austenite fraction. An example of the evolved microstructure can be found in Fig. 4, where a Gleeble ${ }^{\circledR}$ simulated reheated weld metal microstructure is compared to an actual multipass GTA welded root pass of DSS 2205 grade welded with a ER2209 filler consumable.

\section{Actual Gas Tungsten Arc Multipass Welding}

Finally, to investigate the effects of the subsequent passes on the root pass austenite fraction, one set of welding trials was done on the 6-mm-thick SDSS 2507 sheets using automated welding wire feed welding equipment. The sheets were prepared with a 75-deg chamfering and 2-mm root opening to create a single-side V-groove geometry. The filler

Table 2 - Main Alloying Elements of the Used ER2594 Filler Metal*

Filler Metal Grade

ER2594
Main Alloying Elements (wt-\%)

$\begin{array}{cccccccc}\mathrm{Cr} & \mathrm{Ni} & \mathrm{Mn} & \mathrm{Mo} & \mathrm{N} & \mathrm{C} & \mathrm{Si} & \mathrm{Fe} \\ 25.0 & 9.5 & 0.4 & 3.9 & 0.25 & 0.015 & 0.35 & \text { bal. }\end{array}$



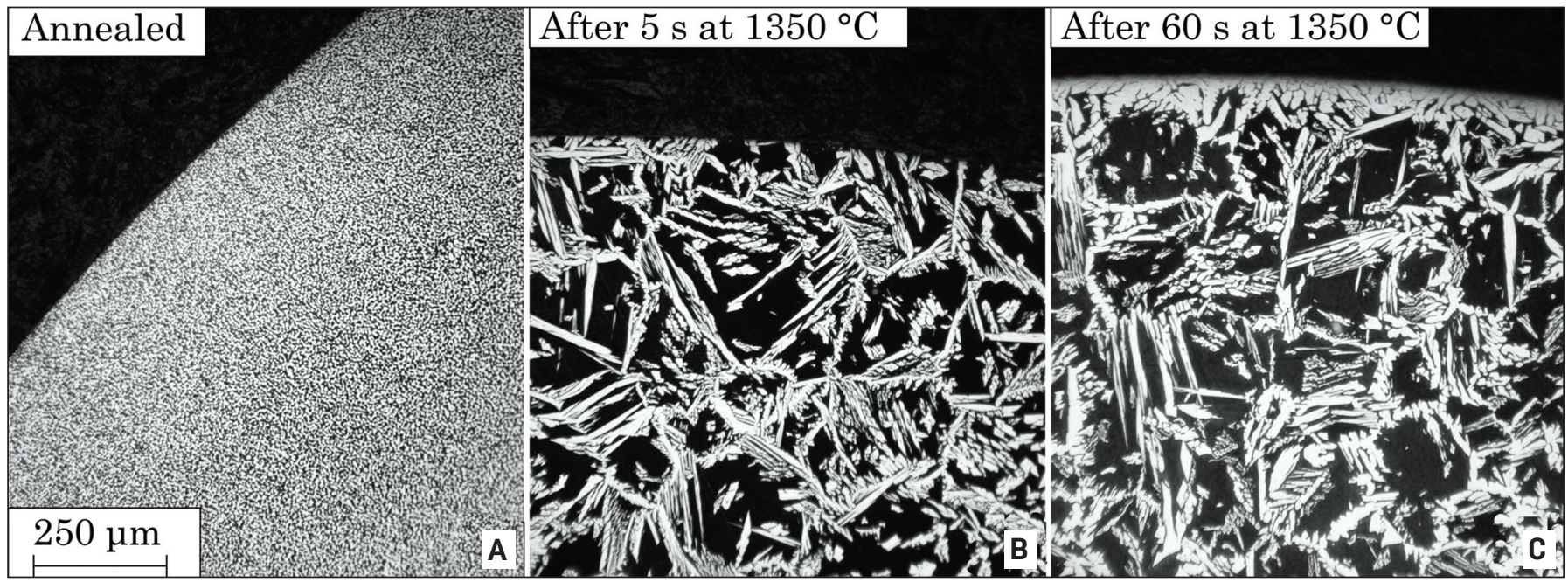

Fig. 7-A - Microstructure of the DSS 2205 rod in the as-received form (annealed); B - the evolved austenitic OD layer thickness after a 5 -s holding time; and $\mathrm{C}-60$-s holding time in nitrogen atmosphere. (The images were taken at the same magnification.)

material used was 1.2-mm-diameter ER2594 for SDSS 2507 (chemical composition from the manufacturer in Table 2).

For the investigation of the effects of the number of subsequent passes above the root pass, different welding parameters were used (Table 3). For all of the welding trials the same $\mathrm{Ar}+2 \mathrm{~N}_{2}$ gas mixture was used with the flow rate of $30 \mathrm{ft}^{3} / \mathrm{h}$ (14 L/min). The root side was protected with argon shielding during the single-pass welds. For the multipass welding trials, a backing plate was used. The root pass cooling rates between the $1200^{\circ}$ and $800^{\circ} \mathrm{C}\left(\mathrm{dT}_{12 / 8}\right)$ were measured using implemented K-type thermocouples, supported by infrared thermal camera measurements. The used tungsten electrode was $2 \%$ thoriated with $1 / 8$ in. $(3.2 \mathrm{~mm}$ ) diameter and ground to a 40-deg electrode angle. The arc length was constant at $2 \mathrm{~mm}$.

\section{Results and Discussion}

\section{Microstructure Evaluation Results}

The austenite fraction of the WM of autogenously welded DSS 2205 sheet with $40 \mathrm{~kJ} / \mathrm{in}$. arc energy was evaluated using three methods: 1) developed image analysis method (Ref. 26), 2) Feritscope ${ }^{\circledR}$ measurements, and 3) ASTM E562 manual point count method. The results are presented in Table 4. For proper investigation, ten images were evaluated in the case of all three methods. In all cases, the same austenite fraction was practically measured.

The highest standard deviation was experienced in the case of the ASTM E562 manual point count method, which represents the subjectivity of the measurement. The differ- ence between the average $\mathrm{A} / \mathrm{F}$ ratio of the image analysis measurements and Feritscope ${ }^{\circledR}$ measurements is $1.4 \%$. Figure 5 represents the correlation between the image analysis method and the Feritscope ${ }^{\circledR}$ measurements, collected from ongoing and previously published (Refs. 26, 30) research. For simplicity and accuracy, the image analysis method is used as the basis for determining the austenite fraction measurements (Ref. 26) for experiments in this research.

\section{Heat-Affected Zone Simulations in a Gleeble ${ }^{\circledR}$ Physical Simulator Results}

The results of the HAZ simulations of DSS 2205 base metal rods are represented in Fig. 6. It was found the cooling rates in the $1200^{\circ}$ to $800^{\circ} \mathrm{C}$ range $\left(\mathrm{dT}_{12 / 8}\right)$ had a more significant effect on the austenite fraction in the simulated HAZ than the total dissolved nitrogen content. All of the duplex stainless steels solidified as delta-ferrite and the ferrite-toaustenite transformation occurred in the solid state (Ref. 1). As the samples were heated to $1350^{\circ} \mathrm{C}$ peak temperature, the initial microstructure was believed to be practically fully ferritic, according to the chromium-nickel pseudobinary phase diagram (Ref. 1). This presupposition was verified on water-quenched samples after 1-s peak temperature holding time. The measured austenite fraction in the waterquenched sample was 9.5 area-\%. The measured austenite fraction in the simulated HAZ varied between 9.5 and 56.4 area- $\%$. The lowest applied cooling rate $\left(\mathrm{dT}_{12 / 8}=10^{\circ} \mathrm{C} / \mathrm{s}\right)$ resulted in the highest austenite fraction (56.4 area-\%), which is close to the DSS 2205 base metal austenite fraction (57.0

Table 3 - The Used Main Welding Parameters for Actual Multipass GTAW Trials

\begin{tabular}{ccccccrr}
$\begin{array}{c}\text { 6-mm-Thick } \\
\text { Sheet Grade }\end{array}$ & $\begin{array}{c}\text { Total Number } \\
\text { of Passes }\end{array}$ & $\begin{array}{c}\text { Welding Current } \\
\text { (A) }\end{array}$ & $\begin{array}{c}\text { Arc Voltage } \\
\text { (V) }\end{array}$ & $\begin{array}{c}\text { Travel Speed } \\
\text { (in./min) }\end{array}$ & $\begin{array}{c}\text { Arc Energy (kJ/in.) and } \\
(\mathrm{kJ} / \mathrm{mm} \text {, in brackets) }\end{array}$ & $\begin{array}{c}\text { Welding Wire } \\
\text { Feed Speed (in./min) }\end{array}$ & $\begin{array}{c}\text { Root Pass } \\
\mathrm{dT}_{12 / 8}\left({ }^{\circ} \mathrm{C} / \mathrm{s}\right)\end{array}$ \\
\hline SDSS & 2 & 170 & 12.3 & 2.0 & $63(2.5)$ & 20 & $35.5 \pm 5.8$ \\
2507 & 4 & 123 & 11.0 & 2.0 & $41(1.6)$ & 15 & $46.5 \pm 2.5$ \\
& 6 & 102 & 10.9 & 2.5 & $27(1.1)$ & 6 & $44.7 \pm 2.9$
\end{tabular}




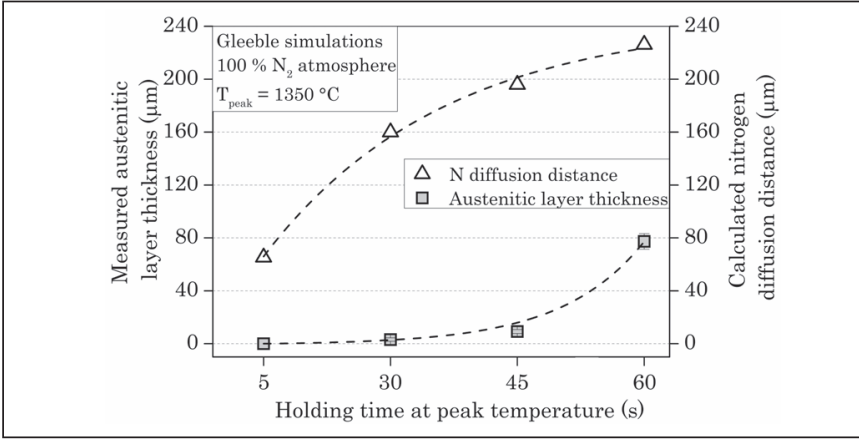

Fig. 8 - Comparison of the calculated atomic nitrogen diffusion distance and the measured austenitic layer thickness.

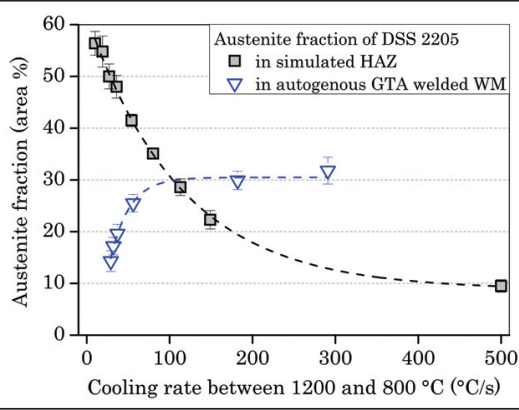

Fig. 10 - Opposite trend of austenite fraction in the HAZ and WM as a function of cooling rate.

area-\%) in as-received (annealed) condition. The increasing $\mathrm{dT}_{12 / 8}$ resulted in decreasing austenite fraction. Cooling rates more than $100^{\circ} \mathrm{C} / \mathrm{s}$ resulted in less than $30 \%$ austenite fraction, which is mostly accepted as the lowest austenite content limit in DSSs (Ref. 5). The measured total nitrogen content of the HAZ simulated samples has not changed compared to the base metals 0.163 wt-\% with the applied cooling rates. These results show the cooling rate has a very significant impact on austenite volume fraction, and nitrogen content does not change in solid-state reheating/cooling over the times and rates investigated.

\section{Pseudo-Nitriding Simulations in a Gleeble ${ }^{\circledR}$ Physical Simulator Results}

The as-received DSS 2205 base metal rod microstructure consists of evenly distributed ferrite and austenite phases Fig. 7A. After a 5-s holding time at $1350^{\circ} \mathrm{C}$ peak temperature in $99.996 \%$ pure nitrogen atmosphere and $50^{\circ} \mathrm{C} / \mathrm{s}$ cooling rate $\left(\mathrm{dT}_{12 / 8}\right)$, a HAZ-like microstructure evolved with an average 43

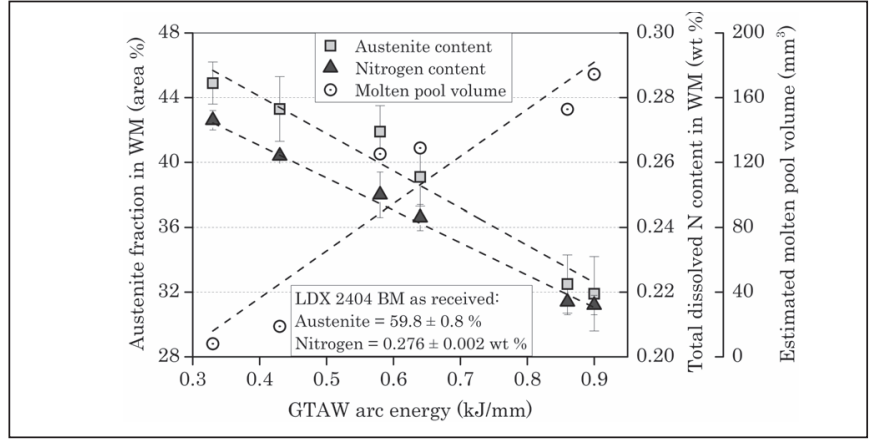

Fig. 9 - The effect of arc energy on the austenite fraction and nitrogen loss in the weld metal.

area-\% austenite fraction - Fig. 7B. On the 5-s held sample, no evolved austenitic layer appeared on the outside diameter by optical microscope analysis. However, a detectable austenitic layer can be seen by optical microscopy when increasing the peak temperature to 30,45 , and $60 \mathrm{~s}$ - Fig. 7C.

The maximum thickness of the evolved austenitic OD layer was measured in the case of the 60-s holding time, which is an average $77.3 \mu \mathrm{m}-$ Fig. 8. In this case, the initial $0.163 \mathrm{wt}-\%$ nitrogen content increased to $0.182 \mathrm{wt}-\%$ of the sample cut out from the cross section. Comparing the calculated atomic nitrogen diffusion distance to the measured austenitic layer thickness (Fig. 8), the calculated distances are much larger at the investigated temperature and holding time. The possible reason for this is the numerical model only calculates with one dimension of nitrogen diffusion in the purely atomic form and in Gleeble ${ }^{\circledR}$ simulations diatomic nitrogen atmosphere presents, which dissociates (Ref. 31).

Our results confirmed diatomic nitrogen could have a significant effect on the evolving microstructure even in a plasma-less environment. This finding can be important when using nitrogen or nitrogen-containing mixtures as backing gas (Refs. 13, 32, 33) and requires more attention in the case of multipass welding, where the root pass is continuously reheated.

\section{Single-Pass Autogenous GTAW with Argon Shielding Gas Results}

The results of austenite fraction in the WM and the total dissolved nitrogen content of the autogenously GTA welded grade LDX 2404 can be seen in Fig. 9. The increasing arc energy resulted in decreasing austenite fraction in the WM. The reason for this is the dissolved nitrogen loss from the base metal (escaping from the molten pool) is increasing with the increasing arc energy (Ref. 23). The low austenite and high fer-

Table 4-Comparison of Different Methods to Determine Phase Ratio in DSS

Base Material

Arc Energy $(\mathrm{kJ} / \mathrm{mm})$

Determined Austenite Fraction in the Weld Metal by Three Methods

$\begin{array}{ccc}\begin{array}{c}\text { Image Analysis } \\ \text { (area \%) }\end{array} & \begin{array}{c}\text { Feritscope }^{\circledR} \\ \text { (\%) }\end{array} & \begin{array}{c}\text { ASTM E562 } \\ \text { (area \%) }\end{array} \\ 30.3 \pm 1.6 & 28.9 \pm 1.9 & 31.6 \pm 2.7\end{array}$




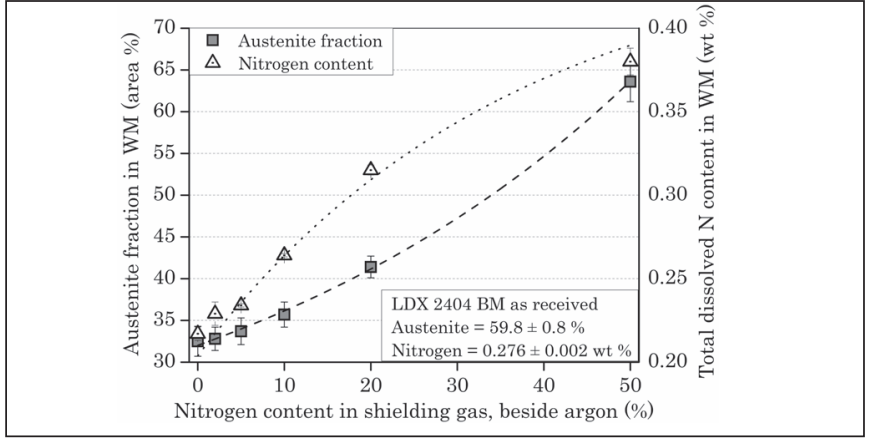

Fig. 11 - The relationship between the austenite fraction and dissolved nitrogen content in the WM and the shielding gas $\mathrm{N}_{2}$ content. The LDX 2404 samples were autogenously GTA welded using $0.86 \mathrm{~kJ} / \mathrm{mm}$ (21.8 $\mathrm{kJ} / \mathrm{in}$.) arc energy.

rite fraction can lead to a degradation of mechanical properties (Ref. 19) and decreasing corrosion resistance (Ref. 34).

The nitrogen loss can be described by the model developed by Du Toit (Ref. 35). According to the model, during the arc welding of high-nitrogen stainless steels (such as DSS), the possible sources of nitrogen that can enter the weld pool are as follows: 1) from the arc atmosphere and 2) from the nitrogen-alloyed base metal. The possible desorption (evolution) of nitrogen can take place 3 ) to the arc plasma, recombining as diatomic $\mathrm{N}_{2}$, and 4) solidifying at the rear of the molten pool, toward the base metal. If the first source of nitrogen (from the arc plasma) is restricted, as in this case of autogenous GTAW with pure argon shielding gas, this absorption-desorption balance is upset.

As a result, nitrogen loss can be measured in the weld metal, which leads to decreasing austenite fraction. The amount of nitrogen loss is proportional to the applied arc energy and the molten pool volume. Figure 9 shows a higher arc energy resulted in a larger molten pool volume, which resulted in lower austenite fraction due to increasing nitrogen loss. Although the Du Toit model (Ref. 35) does not take into account the effects of diatomic nitrogen (see the pseudo-nitriding simulations section) and the interaction between the HAZ and the WM, this model describes the molten pool size effect on the level nitrogen loss.

To compare the different behaviors of HAZ and WM austenite fraction and nitrogen content, one set of autogenous GTAW trials was done on DSS 2205 6-mm sheet, using even improper arc energies (see the single-pass autogenous GTAW with argon shielding gas section). To compare the effect of nitrogen and thermal cycle on the austenite fraction between the HAZ and WM, an infrared thermal camera was used to measure the $\mathrm{dT}_{12 / 8}$ cooling rate in the GTA welded WM during welding. As the chemical composition of the DSS 2205 rods used for Gleeble ${ }^{\circledR}$ simulations and the 6-mmthick DSS 2205 sheets used for autogenous GTAW is the same (with the same 0.160 wt-\% nitrogen content, Table 1), the results can be compared to each other. From Fig. 10, opposite trends can be visible in the austenite fraction as a function of the $\mathrm{dT}_{12 / 8}$ cooling rate between the $\mathrm{HAZ}$ and WM. The austenite fraction monotonically increases in the WM with decreasing heat input (increasing cooling rate), while the austenite fraction monotonically decreases in the $\mathrm{HAZ}$ with decreasing heat input.

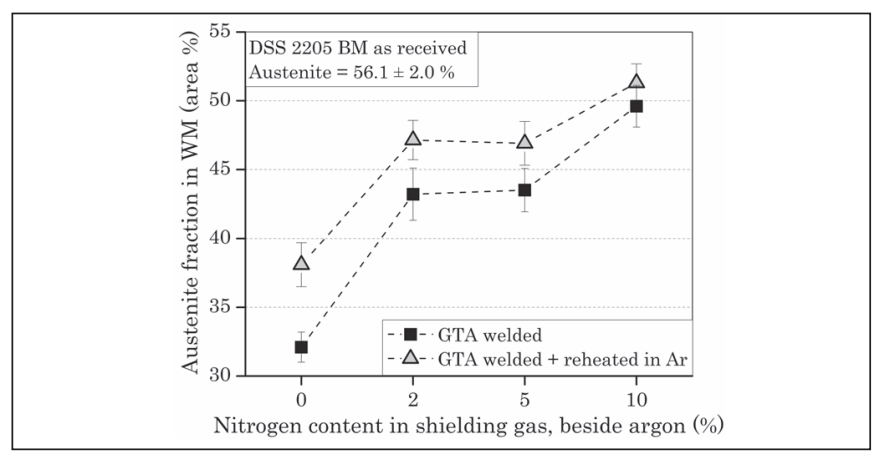

Fig. 12 - The effects of subsequent reheating on the austenite fraction in the WM on the GTA welded (arc energy 0.43 $\mathrm{kJ} / \mathrm{mm}, 11 \mathrm{~kJ} /$ in.) DSS 2205 sheets, welded with different $\mathrm{N}_{2}$ content in the shielding gas.

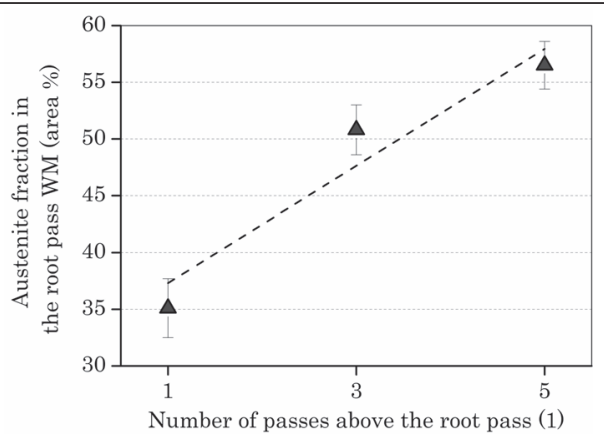

Fig. 13 - The effects of the number of welding passes above the root pass, on the root pass austenite fraction in case of SDSS 2507 heterogeneous GTAW.

Figure 10 suggests that the austenite volume fraction is more sensitive (responsive) to fusion zone weld pool size (i.e., higher cooling rates have smaller weld pool so more retained nitrogen under autogenous welding) than HAZ cooling rates. In the fusion zone, the thermal cycle affects the molten pool volume and thus the nitrogen loss from the molten pool, and the thermal cycle defines the atomic nitrogen diffusion distance in the HAZ (in solid state). The total dissolved nitrogen content remained the same in the case of HAZ simulations (see the heat-affected zone simulations in the Gleeble ${ }^{\circledR}$ physical simulator results section) and decreased in the WM with the increasing heat input (lower cooling rate).

Some of the reasons for this behavior must be based on the increased austenite content in the HAZ at the slower cooling rate, because previously dissolved atomic nitrogen has more time for diffusion and to form austenite. On the other hand, in the weld metal, increasing nitrogen loss is taking place with increased heat input, because nitrogen has more time to escape from the molten pool.

While the reason for this opposite behavior in austenite content between the HAZ and WM is not clear at this point, it is hypothesized that while the volume of HAZ affected in these experiments was more or less the same, cooling rates (determined by the arc energy changes) greatly affected the molten pool size as well (i.e., the area where nitrogen absorption and/or dissolution/evaporation can take place).

More experiments and modeling should be used to verify 
the aforementioned trend. If proven true, the difference in dissolved nitrogen between the two zones could be used in the future to bring an equilibrium to these two zones by a low temperature postweld heat treatment with taking care to sigma phase formation.

\section{Single-Pass Autogenous GTAW with Different Nitrogen Contents in the Shielding Gas Results}

Two sets of welding trials were done on LDX 2404 3-mmthick and DSS 2205 2-mm-thick sheets. In the case of the LDX 2404 base metal, nitrogen containing shielding gas mixtures up to $50 \% \mathrm{~N}_{2}$ content were used. Figure 11 shows the results of austenite fraction and nitrogen content in the WM.

Increasing $\mathrm{N}_{2}$ content in the shielding gas resulted in increasing austenite fraction and dissolved nitrogen content; however, the relationship is not proportional. Because of the solubility and ionization limits of nitrogen, the ideal 50\% austenite and $50 \%$ ferrite phase fraction can hardly be achieved with autogenous welding. More than $30 \% \mathrm{~N}_{2}$ beside argon is needed for the shielding gas to reach $50 \%$ austenite fraction for autogenous GTA welds of LDX 2404 base metal with $0.86 \mathrm{~kJ} / \mathrm{mm}$ arc energy. To reach the base metal's average $\sim 60 \%$ austenite fraction, $\sim 45 \% \mathrm{~N}_{2}$ containing gas mixture should be used with the investigated arc energy. These levels of nitrogen shielding gases are highly impractical and cannot be applied in industrial conditions. Using $10 \% \mathrm{~N}_{2}$ in the shielding gas mixture resulted in almost the same dissolved nitrogen level $(0.264 \mathrm{wt}-\%)$ as in the base metal (0.276 wt-\%). Although the dissolved nitrogen content increased to this level, the austenite fraction remained much lower (35.7 area-\%) than in the base metal. The reason for this is the high dependency of the austenite fraction on the thermal cycle. As the ferrite-to-austenite transformation occurs in the solid state, through a diffusion-driven process, lower cooling rates (higher heat inputs) promote more austenite formation. On the contrary, higher heat inputs will result in larger molten pool volume, which promotes nitrogen loss and results in decreasing austenite fraction (see the single-pass autogenous GTAW with argon shielding gas results section). The balance between nitrogen loss, solubility, shielding gas nitrogen content, and arc energy should be considered variables for future research of DSS autogenous welds. As a result, proper filler material selection and, most importantly, proper welding thermal cycle should be considered when seeking to reach the desired level of $\mathrm{A} / \mathrm{F}$ phase ratio in the WM and HAZ.

\section{Multipass Welding Simulations in a Gleeble ${ }^{\circledR}$ Physical Simulator Results}

A second set of GTAW trials with subsequent solid-state reheating was also done (according to the multipass welding simulations in a Gleeble ${ }^{\circledR}$ physical simulator section) to simulate multipass welding effects on the austenite phase fraction in the WM. The increasing nitrogen content in the shielding gas used for GTAW resulted in increasing austenite fraction in the WM - Fig. 12.

However, as was shown previously (in the single-pass autogenous GTAW with different nitrogen content in the shielding gas results section), the relationship is also not proportional. Between the 2 and $5 \% \mathrm{~N}_{2}$ shielding gas mixtures, practically no austenite fraction increase (an average + 0.1 area-\%) is measurable. The subsequent solid-state reheating (thermal cycle) had more of a significant effect on the microstructure formation between 2 and $5 \% \mathrm{~N}_{2}$. The largest increase, $+6 \%$ austenite fraction, is measured in the case of the argon shielding welded WM. We hypothesized that the reason for this is the secondary austenite $\left(\gamma_{2}\right)$ formation, related to the previously formed chromium nitride $\left(\mathrm{Cr}_{2} \mathrm{~N}\right)$ precipitations. The argon shielded WM showed the lowest average austenite fraction (32.1 area-\%) in the aswelded condition. This means the dissolved atomic nitrogen in the molten pool remained in the relatively large $(\sim 300$ $\mu \mathrm{m})$ ferrite grains during solidification. As the solubility limit of nitrogen in delta-ferrite is very low $(0.01 \mathrm{wt}-\%$ at $700^{\circ} \mathrm{C}$ (Ref. 1)) and the delta-ferrite has a lot of chromium, the trapped nitrogen precipitate as $\mathrm{Cr}_{2} \mathrm{~N}$ (Ref. 36). The $\mathrm{Cr}_{2} \mathrm{~N}$ precipitations are in relationship with the $\gamma_{2}$ formation (Refs. 37, 38). For the evolution of $\gamma_{2}$ from $\mathrm{Cr}_{2} \mathrm{~N}$, a model was developed by Zhiqiang et al. (Ref. 39). They stated e $\mathrm{Cr}_{2} \mathrm{~N}$ precipitations will occur in the nitrogen supersaturated delta-ferrite, which are not stable at the $\gamma_{2}$ formation temperature (see Ellingham's diagram for nitrides). During reheating above $950^{\circ} \mathrm{C}$, the $\mathrm{Cr}_{2} \mathrm{~N}$ growth will cause $\mathrm{Cr}$ depletion and $\mathrm{Ni}$ enrichment in the surroundings, which is favorable for $\gamma_{2}$ formation. When $\gamma_{2}$ nucleates, $\mathrm{Cr}_{2} \mathrm{~N}$ can dissolve due to the short diffusion path of nitrogen.

Figure 12 also shows that a higher $\mathrm{N}_{2}$ shielding gas resulted in higher austenite fraction ( 48.5 area-\% in the case of the $10 \% \mathrm{~N}_{2}$ welded sample), where the solid-state reheating only had a minor effect on the microstructure $(+2 \%$ austenite). As the initial, as-welded microstructure had more austenite fraction, the dissolved atomic nitrogen could diffuse to the austenite phases during solid-state phase transformation. As the solubility of nitrogen is much larger in austenite than in delta-ferrite $\left(\sim 0.4 \mathrm{wt}-\%\right.$ at $1100^{\circ} \mathrm{C}$ (Ref. $1)$ ), the trapped nitrogen can dissolve in austenite, and less atomic nitrogen in delta-ferrite will form $\mathrm{Cr}_{2} \mathrm{~N}$, which later can promote $\gamma_{2}$ formation.

\section{Actual Gas Tungsten Arc Multipass Welding Results}

To verify the reheating effects on the evolving microstructure, actual heterogeneous GTAW trials (see the actual gas tungsten arc multipass welding section) were done on high-nitrogen alloyed superduplex stainless steel SDSS 2507 (Table 1). Figure 13 shows the austenite fraction increases in the root pass WM with increasing subsequent passes (lower heat input per pass).

This finding needs great attention by industrial partners. For example, welding heavy-walled DSS pipes with multiple welding passes can lead to difficulties in the prediction of the $\mathrm{A} / \mathrm{F}$ phase ratio of the root pass. As the subsequent reheating cycles will mean increasing austenite fraction in the root pass, a highly austenitic microstructure can form at the contact surface of the stored product. A very high austenite fraction (more than $70 \%$ ) can lead to higher susceptibility to stress corrosion cracking (Ref. 40) and a possible corrosion degradation of the weld root. Moreover, the diatomic nitrogen also 
influences the surface microstructure (as shown in the pseudo-nitriding simulations in the Gleeble ${ }^{\circledR}$ physical simulator results section). Thus, pure nitrogen as a backing gas needs to be considered for welding procedures in pipe welding.

\section{Conclusions}

Several of the objectives of this work have been confirmed by other researchers, but a few new conclusions also arose from this work. From the simulation results, the following conclusions can be drawn:

- The cooling rate between $1200^{\circ}$ and $800^{\circ} \mathrm{C}\left(\mathrm{dT}_{12 / 8}\right)$ had a significant effect on the austenite fraction of the simulated HAZs. Austenite fraction close to the initial base metal microstructure was measured in the case of $\mathrm{dT}_{12 / 8}=10^{\circ} \mathrm{C} / \mathrm{s}$. On the other end, the water-quenched samples with $\mathrm{dT}_{12 / 8}=$ $500^{\circ} \mathrm{C} / \mathrm{s}$ resulted in an almost fully ferritic microstructure. The total dissolved nitrogen content in the HAZ simulated samples did not change significantly.

- The diatomic nitrogen had an effect on the microstructure in a plasma-less environment at high peak temperatures and longer holding times than what normally occurs in the case of arc welding. Diatomic nitrogen could dissociate and diffuse into the microstructure, resulting in a fully austenitic outside layer with a thickness of $\sim 70 \mu \mathrm{m}$ after $60 \mathrm{~s}$.

- Multipass welding simulations showed solid-state reheating of as-welded microstructures will result in an increase in austenite fraction in the WM. The degree of austenite fraction growth depends on the nitrogen content of the shielding gas used for the initial welding. Higher nitrogen content in the shielding gas will result in higher initial austenite fraction in the WM and less austenite fraction growth after the subsequent solid-state reheating.

From the GTAW results, the following conclusions can be drawn:

- In the case of autogenous GTAW with argon shielding, a higher arc energy creates a higher molten pool volume, which resulted in increasing nitrogen loss. The nitrogen loss from the molten pool caused a lower austenite fraction in the WM after cooling to room temperature.

- Opposite trends in austenite fraction of the WM and $\mathrm{HAZ}$ can be measured. The lower $\mathrm{dT}_{12 / 8}$ cooling rate (higher arc energy) resulted in decreasing austenite fraction in the WM because of nitrogen loss from the molten pool. On the other hand, the lower $\mathrm{dT}_{12 / 8}$ cooling rate resulted in an increasing austenite fraction in the HAZ because there was more time for nitrogen diffusion during the solid-state ferrite-to-austenite phase transformations.

- In the case of autogenous GTAW of LDX 2404 duplex stainless steel with argon and nitrogen mixture shielding, the increasing nitrogen content in the shielding gas resulted in increased austenite fraction in the WM. However, impractical ( $45 \% \mathrm{~N}_{2}$ ) nitrogen levels in the shielding gas resulted in ideal austenite-to-ferrite phase balance because of the solubility and ionization limits of nitrogen. Thus, the thermal cycle has the most significant effect on the evolving microstructure.

- Actual multipass heterogeneous GTAW of SDSS 2507 superduplex stainless steel showed an increased number of welding passes resulted in increasing austenite fraction in the root pass microstructure, which needs great attention from industrial partners.
Separation of atomic from molecular nitrogen effects was partially successful in this work. More work needs to be performed in this area, with emphasis on finding the volume fraction of nitrides, another trap of the missing atomic nitrogen needed to stabilize austenite on cooling. Yet, it became obvious that controlling thermal cycles is a more effective way of obtaining reproducible duplex stainless steel welds.

\section{Acknowledgments}

The authors would like to thank Dr. Ben Pletcher from Bechtel Corp., Houston, Tex., for funding part of this research and invaluable technical input. Thanks also go to Dr. Elin Westin, voestalpine Böhler Welding, Austria, for her expertise and helpful discussions. We'd also like to recognize Outokumpu Corp. and voestalpine Böhler Welding USA for providing base and filler metals for the welding experiments. Parts of this paper have been supported by the János Bolyai Research Scholarship of the Hungarian Academy of Sciences grant number Bo/00196/16/6 and National Research, Development and Innovation Office - NKFIH, OTKA PD 120865 (K. Májlinger).

\section{References}

1. Lippold, J. C., and Kotecki, D. J. 2005. Welding Metallurgy and Weldability of Stainless Steels. John Wiley \& Sons Inc.

2. Kotecki, D. J., and Siewert, T. A. 1992. WRC-1992 constitution diagram for stainless steel weld metals: A modification of the WRC-1988 diagram. AWS Annual Meeting, 171-178. aws.org/wj/ supplement/WJ_1992_05_s171.pdf

3. DeLong, W. T. 1974. Ferrite in austenitic stainless steel weld metal. Welding Journal 53(7): 273-s to 286-s.

4. Varol, I., Lippold, J. C., and Baeslack, W. A. 1992. Welding of duplex stainless steels. Key Engineering Materials 69-70: 217-252. DOI: https://doi.org/10.4028/www.scientific.net/KEM.69-70.217

5. Gunn, R. N. 1997. Duplex Stainless Steels: Microstructure, Properties and Applications. Abington Publishing.

6. Hertzman, S. 2001. The influence of nitrogen on microstructure and properties of highly alloyed stainless steel welds. ISIJ International 41(6): 580-589. DOI: https://doi.org/10.2355/ isijinternational.41.580

7. Leif, K. 1999. Intermetallic phase precipitation in duplex stainless steels and weld metals. Welding Research Council Bulletin 43(438): 1-23.

8. Armas, I. A., and Degalaix, S. M. 2009. Duplex Stainless Steels. Wiley-ISTE. DOI: https://doi.org/10.1533/9781845698775

9. Hertzman, S., and Charles, J. 2011. On the effect of nitrogen on duplex stainless steels. Revue de Métallurgie 108(7-8): 413-425. DOI: https://doi.org/10.1051/metal/2011071

10. Trube, S., and Ammann, Th. 2001. Schutzgase zum schweißen und formieren von $\mathrm{CrNi}$-stählen (shielding gases for welding and root shielding of chrome nickel steels). Jahrbuch schweißtechnik, DVS-Verlag, Düsseldorf.

11. Sales, A. M., Westin, E. M., and Jarvis, B. L. 2017. Effect of nitrogen in shielding gas of keyhole GTAW on properties of duplex and superduplex welds. Welding in the World 61(6): 1133-1140. DOI: https://doi.org/10.1007/s40194-017-0486-1

12. Bhatt, R. B. B., Kamat, H. S. S., Ghosal, S.K. K., and De, P. K. K. 1999. Influence of nitrogen in the shielding gas on corrosion resistance of duplex stainless steel welds. Journal of Materials Engineering and Performance 8(5): 591-597. DOI: https://doi.org/ $10.1361 / 105994999770346648$ 
13. Westin, E. M., Johansson, M. M., Bylund, L.-A. A., and Pettersson, R. F. A. 2014. Effect on microstructure and properties of super duplex stainless steel welds when using backing gas containing nitrogen and hydrogen. Welding in the World 58(3): 347-354. DOI: https://doi.org/10.1007/s40194-014-0120-4

14. Li, J., Ma, Z., Xiao, X., Zhao, J., and Jiang, L. 2011. On the behavior of nitrogen in a low-Ni high-Mn super duplex stainless steel. Materials and Design 32(4): 2199-2205. DOI: https://doi.org/ 10.1016/j.matdes.2010.11.021

15. Weber, L., and Uggowitzer, P. J. 1998. Partitioning of chromium and molybdenum in super duplex stainless steels with respect to nitrogen and nickel content. Materials Science and Engineering: A 242(1): 222-229. DOI: https://doi.org/10.1016/S09215093(97)00521-2

16. Migiakis, K., and Papadimitriou, G. D. 2009. Effect of nitrogen and nickel on the microstructure and mechanical properties of plasma welded UNS S32760 super-duplex stainless steels. Journal of Materials Science 44(23): 6372-6383. DOI: https://doi.org/ $10.1007 / \mathrm{s} 10853-009-3878-9$

17. Kotecki, D. J. 2010. Some pitfalls in welding of duplex stainless steels. Soldagem \& Inspeção 15(4): 336-343. DOI: https://doi. org/10.1590/S0104-92242010000400011

18. Kokawa, H., Tsory, E., and North, T. H. 1995. Duplex stainless steel weld metal. ISIJ International 35(10): 1277-1283. DOI: https://doi.org/10.2355/isijinternational.35.1277

19. Valiente Bermejo, M. A., Karlsson, L., Svensson, L-E., Hurtig, K., Rasmuson, H., Frodigh, M., and Bengtsson, P. 2015. Effect of shielding gas on welding performance and properties of duplex and superduplex stainless steel welds. Welding in the World 59(2): 239-249. DOI: https://doi.org/10.1007/s40194-014-0199-7

20. Muñoz, I., García Antón, A. J., Guiñón, J. L., and Pérez Herranz, V. 2005. Effect of nitrogen in argon as a shielding gas on tungsten inert gas welds of duplex stainless steels. Corrosion 61(7): 693-705. DOI: https://doi.org/10.5006/1.3278204

21. Başyiğit, A., and Adem, K. 2018. The effects of nitrogen gas on microstructural and mechanical properties of TIG welded S32205 duplex stainless steel. Metals 8(4): 226. DOI: https://doi. org/10.3390/met8040226

22. Keskitalo, M., Mantyjarvii, K., Sundqvist, J., Powell, J., Kaplan, A. F. H., Mäntyjärvi, K., Sundqvist, J., Powell, J., and Kaplan, A. F. H. 2015. Laser welding of duplex stainless steel with nitrogen as shielding gas. Journal of Materials Processing Technology 216: 381-384. DOI: https://doi.org/http://dx.doi.org/10.1016/ j.jmatprotec.2014.10.004

23. Hosseini, V. A., Wessman, S., Hurtig, K., and Karlsson, L. 2016. Nitrogen loss and effects on microstructure in multipass TIG welding of a super duplex stainless steel. Materials and Design 98: 88-97. DOI: https://doi.org/10.1016/j.matdes.2016.03.011

24. Leif, K. 2010. Welding duplex stainless steels — Old truths and new grades. $8^{\text {th }}$ Duplex Stainless Steels Conference.

25. Elmer, J. W. 2015. The effect of $\mathrm{Ar}$ and $\mathrm{N}_{2}$ shielding gas on laser weld porosity in steel, stainless steels, and nickel. Welding Journal 94(10): 313-s to 325-s.

26. Varbai, B., Pickle, T., and Májlinger, K. 2018. Development and comparison of quantitative phase analysis for duplex stainless steel weld. Periodica Polytechnica Mechanical Engineering 62(3): 247253. DOI: https://doi.org/10.3311/PPme.12234

27. Standard test method for determining volume fraction by systematic manual point count. ASTM E562 - 11. DOI: https://doi. org/10.1520/E0562-11.2

28. Standard test methods for determination of carbon, sulfur, nitrogen, and oxygen in steel and in iron, nickel, and cobalt alloys 1. ASTM E1019. DOI: https://doi.org/10.1520/E1019-11

29. Hertzman, S., Ferreira, P. J., and Brolund, B. 1997. An experimental and theoretical study of heat-affected zone austenite reformation in three duplex stainless steels. Metallurgical and Materials Transactions A 28 (February): 277-285. DOI: https://doi.org/
$10.1007 /$ s11661-997-0130-6

30. Varbai, B., and Májlinger, K. 2018. Thermoelectric power measurements on duplex stainless steel weldments. Lecture Notes in Mechanical Engineering, 789-799. DOI: https://doi.org/ 10.1007/978-3-319-75677-6_67

31. Lino da Silva, M., Guerra, V., and Loureiro, J. 2007. Twotemperature models for nitrogen dissociation. Chemical Physics 342 (1-3): 275-287. DOI: https://doi.org/10.1016/j.chemphys. 2007.10.010

32. Sales, A. M., Westin, E. M., and Colegrove, P. 2016. Effect of nitrogen in backing gas on duplex root weld properties of heavywalled pipe. Welding in the World 60(5): 877-882. DOI: https://doi.org/10.1007/s40194-016-0347-3

33. Westin, E. M., Johansson, M. M., and Pettersson, R. F. A. 2013. Effect of nitrogen-containing shielding and backing gas on the pitting corrosion resistance of welded lean duplex stainless steel LDX 2101((R)) (EN 1.4162, UNS S32101). Welding in the World 57(4): 467476. DOI: https://doi.org/10.1007/s40194-013-0046-2

34. da Fonseca, G., Barbosa, L., Ferreira, E., Xavier, C., and de Castro, J. 2017. Microstructural, mechanical, and electrochemical analysis of duplex and superduplex stainless steels welded with the autogenous TIG process using different heat input. Metals 7(12): 538. DOI: https://doi.org/10.3390/met7120538

35. Du Toit, M. 2001. The behaviour of nitrogen during the autogenous arc welding of stainless steel. University of Pretoria.

36. Pettersson, N., Pettersson, R. F. A., and Wessman, S. 2015. Precipitation of chromium nitrides in the super duplex stainless steel 2507. Metallurgical and Materials Transactions A: Physical Metallurgy and Materials Science 46(3): 1062-1072. DOI: https://doi. org/10.1007/s11661-014-2718-y

37. Ramirez, A. J., Brandi, S. D., and Lippold, J. C. 2004. Secondary austenite and chromium nitride precipitation in simulated heat affected zones of duplex stainless steels. Science and Technology of Welding and Joining 9(4): 301-313. DOI: https://doi.org/ 10.1179/136217104225021715

38. Ramirez, A. J., Lippold, J. C., and Brandi, S. D. 2003. The relationship between chromium nitride and secondary austenite precipitation in duplex stainless steels. Metallurgical and Materials Transactions A 34(8): 1575-1597. DOI: https://doi.org/10.1007/ s11661-003-0304-9

39. Zhang, Z., Jing, H., Xu, L., Han, Y., Zhao, L., and Zhang, J. 2017. Influence of microstructure and elemental partitioning on pitting corrosion resistance of duplex stainless steel welding joints. Applied Surface Science 394: 297-314. DOI: https://doi.org/ 10.1016/j.apsusc.2016.10.047

40. Chehuan, T., Dreilich, V., de Assis, K. S., de Sousa, F. V. V., and Mattos, O. R. 2014. Influence of multipass pulsed gas metal arc welding on corrosion behaviour of a duplex stainless steel. Corrosion Science 86: 268-274. DOI: https://doi.org/http://dx.doi.org/ 10.1016/j.corsci.2014.06.004

BALÁZS VARBAI (varbai@eik.bme.hu) and KORNÉL MÁLINGER are with the Budapest University of Technology and Economics, Budapest, Hungary. YONI ADONYI, RICHARD BAUMER, and TIMOTHY PICKLE are with LeTourneau University, Longview, Tex. JÁNOS DOBRÁNSZKY is with the MTA-BME Research Group for Composite Science and Technology, Budapest, Hungary. 